Revista

v. 11 n. 3 de 2020

Observatorium

1984-4891

ensaio

\title{
Aline Lages
}

Artista Plástica

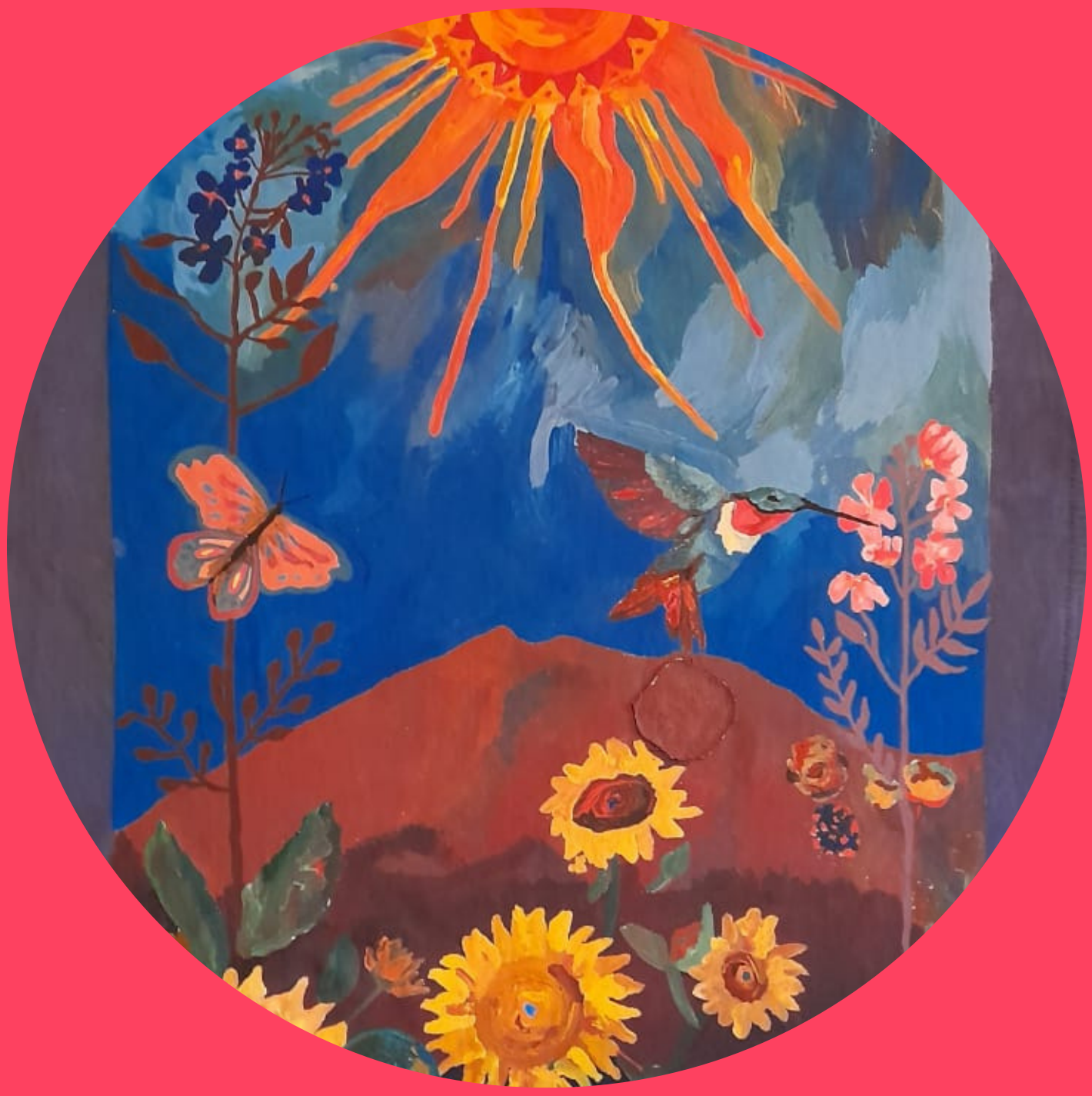

alinelagesthomazeyahoo.com

ealinethomazlages

Dom Joaquim-MG 

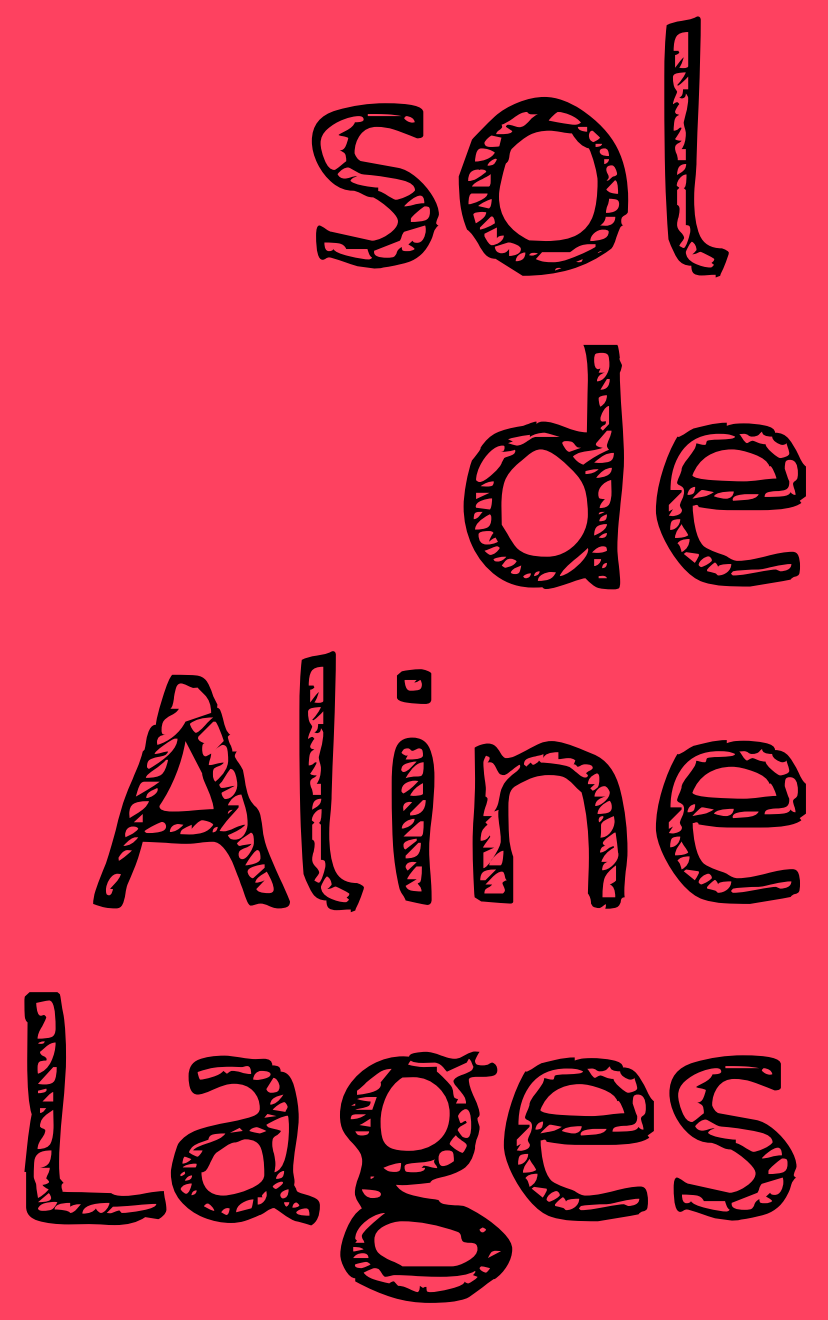


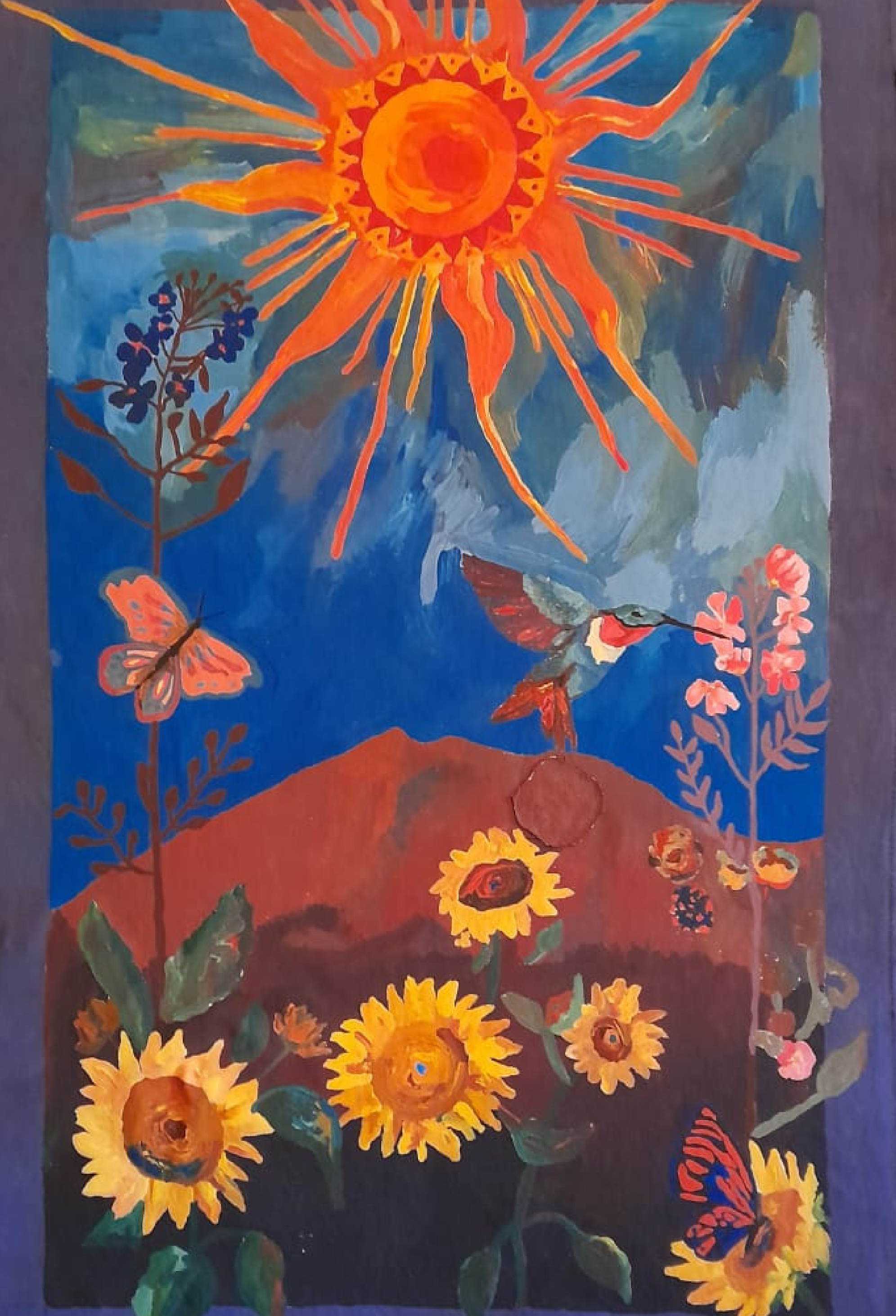




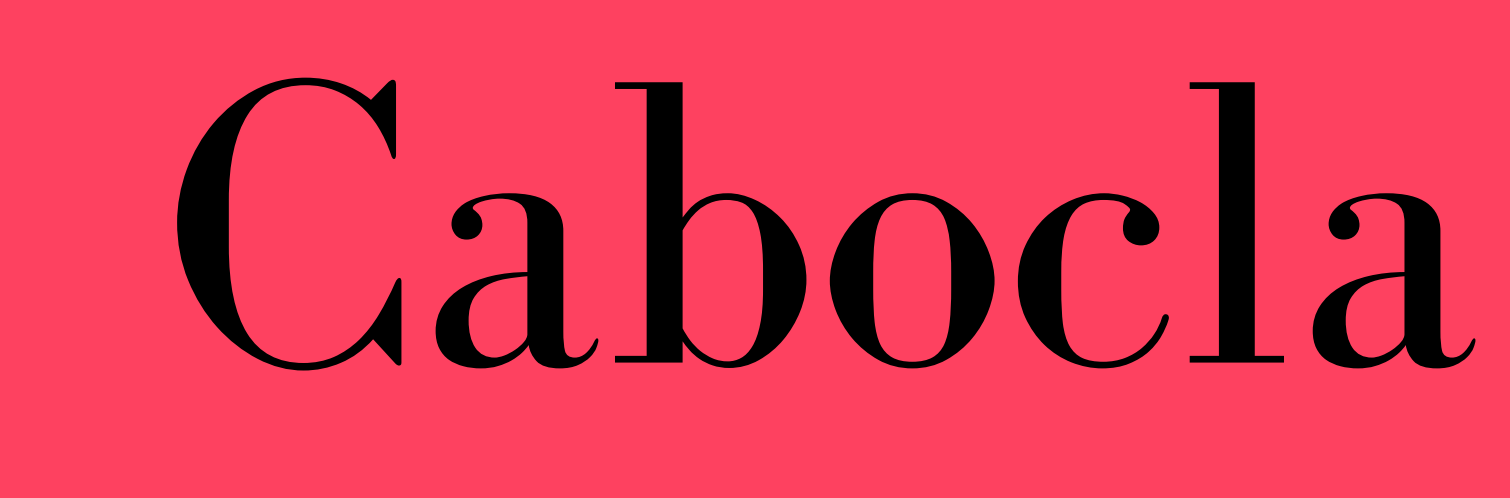

Obra de Aline Lages

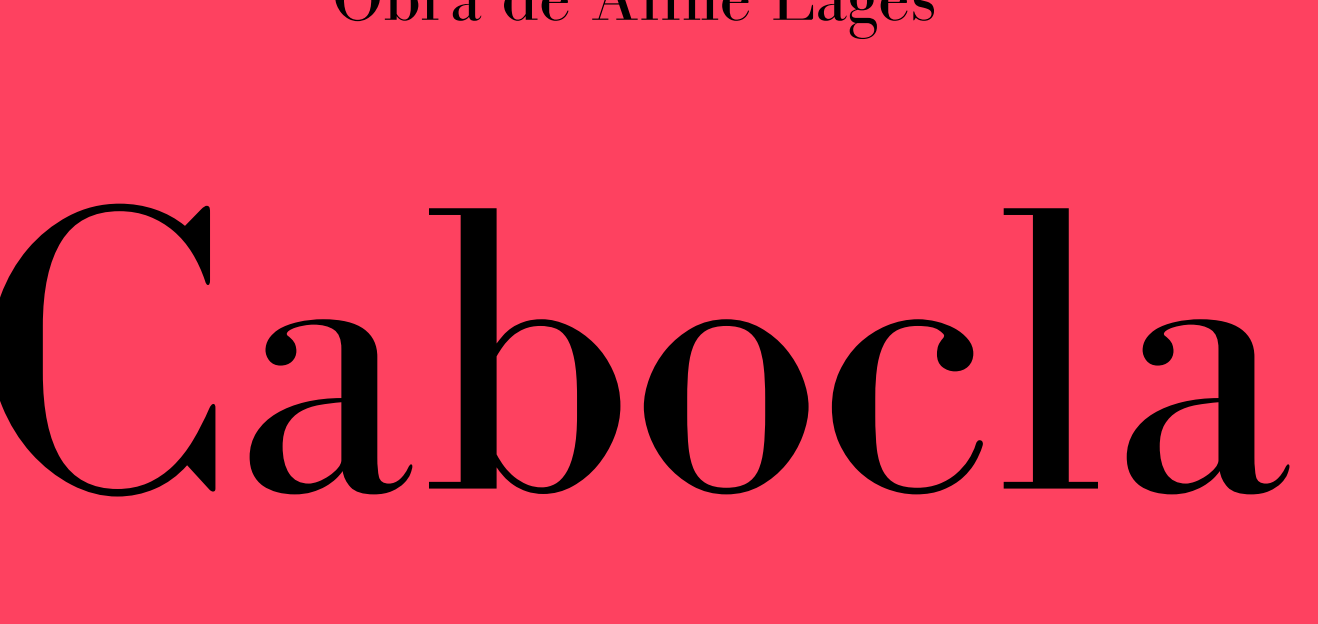

ictio

,
西 


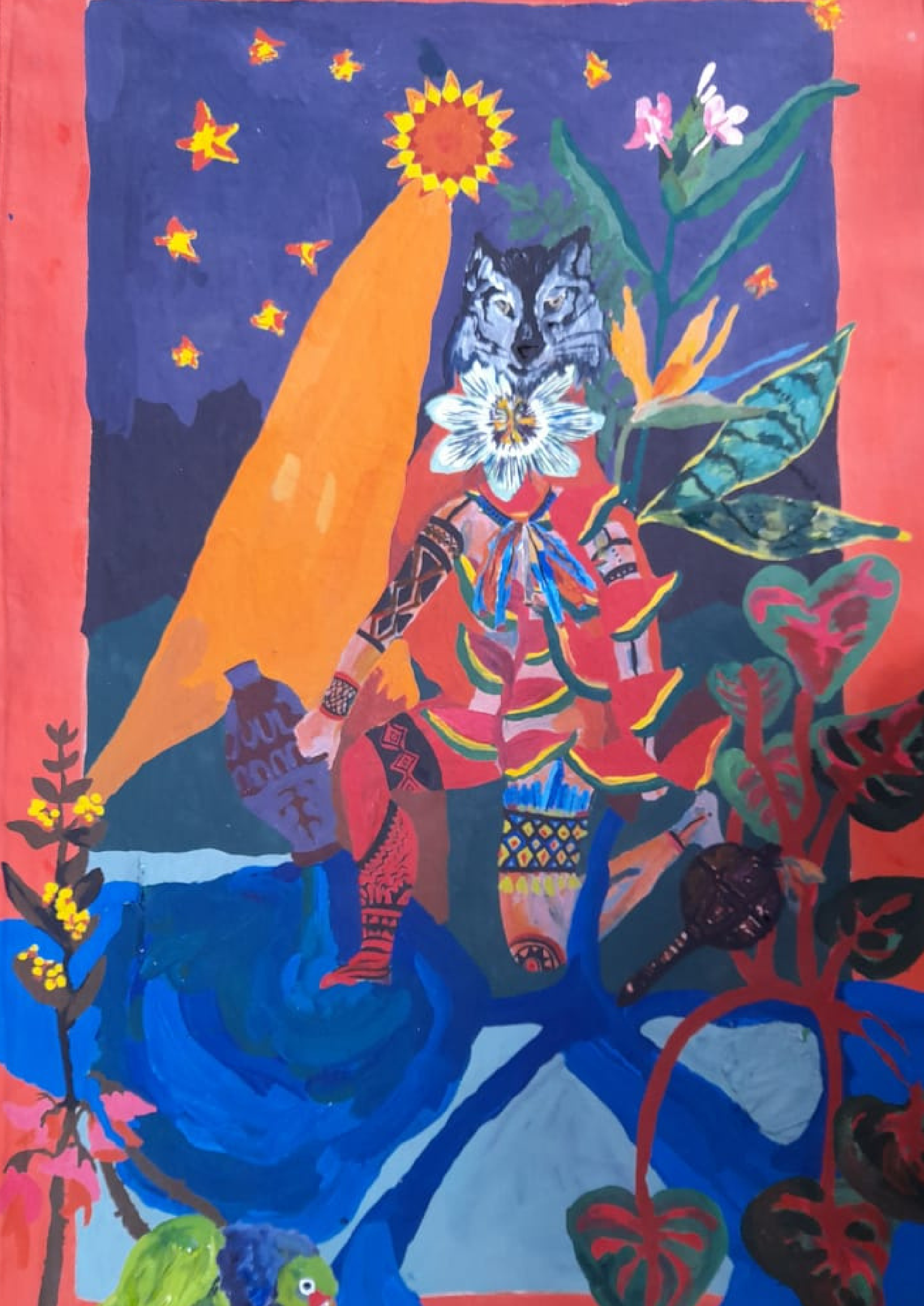

